\title{
Modeling the potential climate change- induced impacts on future genus Rhipicephalus (Acari: Ixodidae) tick distribution in semi-arid areas of Raya Azebo district, Northern Ethiopia
}

\author{
Meseret Hadgu ${ }^{1,2^{*}}$, Habtamu Taddele Menghistu²,3, Atkilt Girma ${ }^{2,4}$, Haftu Abrha² and Haftom Hagos ${ }^{2}$
}

\begin{abstract}
Background: Climate change is believed to be continuously affecting ticks by influencing their habitat suitability. However, we attempted to model the climate change-induced impacts on future genus Rhipicephalus distribution considering the major environmental factors that would influence the tick. Therefore, 50 tick occuance points were taken to model the potential distribution using maximum entropy (MaxEnt) software and 19 climatic variables, taking into account the ability for future climatic change under representative concentration pathways (RCPs) 4.5 and 8.5, were used.

Results: MaxEnt model performance was tested and found with the AUC value of 0.99 which indicates excellent goodness-of-fit and predictive accuracy. Current models predict increased temperatures, both in the mid and end terms together with possible changes of other climatic factors like precipitation which may lead to higher tickborne disease risks associated with expansion of the range of the targeted tick distribution. Distribution maps were constructed for the current, 2050, and 2070 for the two greenhouse gas scenarios and the most dramatic scenario; RCP 8.5 produced the highest increase probable distribution range.

Conclusions: The future potential distribution of the genus Rhipicephalus show potential expansion to the new areas due to the future climatic suitability increase. These results indicate that the genus population of the targeted tick could emerge in areas in which they are currently lacking; increased incidence of tick-borne diseases poses further risk which can affect cattle production and productivity, thereby affecting the livelihood of smallholding farmers. Therefore, it is recommended to implement climate change adaptation practices to minimize the impacts.
\end{abstract}

Keywords: Cattle ticks, Climate change, Modeling, MaxEnt, RCPs, WorldClim

\section{Background}

Climate is a major factor that determines agricultural production including livestock production, hydrologic balances, input supplies, and other components of agricultural systems (Aydinalp and Cresser, 2008).

The livestock sector is sensitive to climate change, and it is expected that its production and productivity

\footnotetext{
* Correspondence: meserethadgu2006@gmail.com

${ }^{1}$ Tigray Agricultural Marketing Promotion Agency, Mekelle, Ethiopia

${ }^{2}$ Institute of Climate and Society, Mekelle University, Mekelle, Ethiopia

Full list of author information is available at the end of the article
}

performance is to be influenced directly by initiating factors like vectors and vector-borne diseases that can cause significant losses in this sector (Calvosa et al., 2009). The same study reported that the African livestock population will have an indirect damage by 2020 due to the direct impacts of parasites and their pathogens. The overall impacts on livestock production result in a decline in production and productivity performance as well as the export capacity of Ethiopia (Thornton et al., 2009), and it is a huge threat for many who rely on this sector (Gashaw, 2014). 
A changing climate in the future may affect livestock production directly by hampering physiological performance. For example, excessive temperature can affect the production and productivity performance of animals indirectly by favoring certain vectors and vector-borne diseases (Min et al., 2011). The temperature and rainfall patterns in East Africa have been changing in the past two decades (Parry et al., 2007). This has been affecting the livestock in general and cattle production in particular through direct influence on the distribution of organisms like the tick species (Hoffmann, 2010). The IPCC report also claims that among other consequences, climate change will change the range of some of the vectors and vector-borne infectious diseases (Parry et al., 2007).

Ticks are the most economically important parasites and obligate hematophagous ectoparasites of domestic animals in general and large animals like cattle in particular (de la Fuente et al., 2006). As many other arthropods, ticks are classified under the suborder Ixodida distributed widely in the world and they are very sensitive to climate due their dependence and spend most of their life cycle stages on a complex combination of climate variables for development and survival (Cumming, 2002). Therefore, changing of climate probably have great contributions in defining their abundance and distribution (faster development and lower mortality) and the probability to survive in a new area as the major driver in a given territory (Cumming, 2002; Ogden et al., 2004).

Many recent studies have investigated the influence of climate change on tick expansion in the different parts of the world (Parola et al., 2008). It has been implicated as an important driving force for the expansion of tick habitat and the incidence of tick-borne diseases (Tokarevich et al., 2011), and it is globally a limiting factor in the distribution of tick and tick-borne diseases (Ogden et al., 2005). It is also recognized that ticks are spreading to higher altitudes as a result of the effects of climate change (Léger et al., 2013; Mannelli et al., 2012; Medlock et al., 2013).

Describing the spatial patterns of vector and vector-borne diseases and guiding the planning of external parasites like tick control are now well established with the bold role of risk mapping and have been demonstrated for a range of major parasitic diseases (Hay et al., 2000). Besides, modeling the spatial distribution of vectors and vector-borne diseases is becoming crucial to understand the environmental determinants of infection as well as for guiding the planning of control programs (Slater, 2012). A focus in vector distribution modeling has expanded to evaluating the potential for the establishment and spread of invasive vector species and assessing vector species responses to global climate change (Gonzalez, 2010; Roura-Pascual, 2008; Ward, 2007). However, there is still a gap to identify and document the future impact of climate change on cattle tick distribution.
Therefore, modeling climate change-induced impacts on cattle tick distribution will add a new insight to the research environment using the species distribution model (SDM) in order to give recommendations on controlling the species expansion.

\section{Materials and methods \\ Study area}

The cross-sectional study was conducted from January to December 2016 in the semi-arid areas of Raya Azebo district which is located at $12^{\circ} 47^{\prime} 55^{\prime \prime}$ north and $039^{\circ} 38^{\prime}$ $45^{\prime \prime}$ east. The district is found to be about $128 \mathrm{~km}$ south far from Mekelle, the capital city of Tigray Region, Ethiopia (Fig. 1). It is also about $662 \mathrm{~km}$ north away from Addis Ababa, the capital city of Ethiopia. The agro-climate of the district is classified as midland (80.6\%), lowland (18\%), and highland (1.4\%) (Bewket, 2015). The altitude of the district ranges from 923 up to $2300 \mathrm{~m}$ a.s.l (Ethio-DEM 90).

\section{Climate characterization of the district}

Raya Azebo district is one of the drought-prone and food insecure districts of Tigray regional state (Bewket, 2015). According to the 30 years raw climate data (Temperature and Precipitation data starting from 1980 to 2009) obtained from NMA of Ethiopia, we characterize the climate of the district as the monthly rainfall varied from 10.9 up to $195 \mathrm{~mm}$ which is less than the monthly evapotranspiration which ranges from 187 to $262 \mathrm{~mm}$. The monthly average evapotranspiration recorded was $222 \mathrm{~mm}$ and exceeds the monthly average rainfall which was $57 \mathrm{~mm}$. The mean monthly minimum and maximum temperatures range from 12.9 to $18^{\circ} \mathrm{C}$ and 26.8 to $31.5^{\circ} \mathrm{C}$, respectively, and the annual average mean temperature reaches $22^{\circ} \mathrm{C}$. The district also experiences very high evapotranspiration (Fig. 2). It is estimated that the monthly annual ET is about $1712 \mathrm{~mm} /$ year, with an average even distribution of $57.08 \mathrm{~mm}$ every month, and it exceeds the annual average rainfall which is $685.2 \mathrm{~mm} /$ year with an average even distribution of $22.84 \mathrm{~mm} / \mathrm{month}$.

\section{Data types, sources, and analysis approach Tick presence data}

This study was based on the presence and occurrence points of the ixodid ticks of cattle breeds in the semiarid areas of Raya Azebo. Tick presence data was checked from the previous research conducted in the same study area by Hadgu et al. (2018). According to this study report, out of the $90 \%$ tick prevalence reported, six tick species that belong to the genera of Rhipicephalus (54\%), Boophilus (5\%), Amblyomma (3\%), and Hyalomma (2.7\%) were identified and the most dominant tick genus Rhipicephalus (54\%) was taken as 


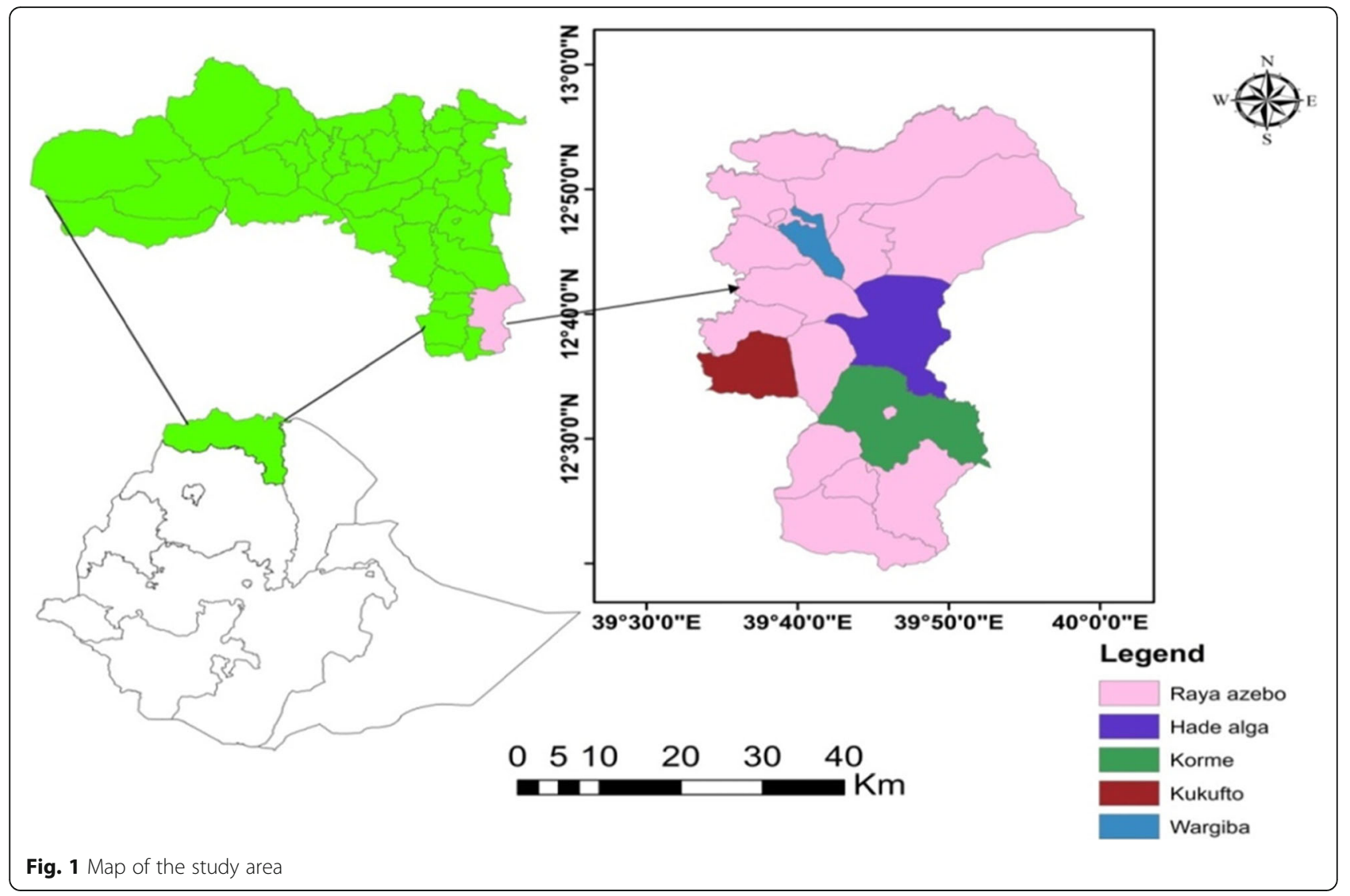

the study target in the present study. Therefore, having the above tick presence data, geo-referenced locations, or occurrence points that represent the genus Rhipicephalus of cattle tick was recorded in terms of coordinate pair as decimal latitude/longitude in the WGS84 system where the cattle population is supposed to be positive for tick presence examination using a hand-held GPS (Garmin eTrex device). Based on this, 50 GPS records or location points for the sampling sites were collected and used to run the model. Even though a bit few geographic points were recorded, models built with few points, while not as accurate as those built with large datasets and potentially not appropriate for all applications, are still useful (Hernandez et al., 2006). In line with this, it has been indicated that after 50 points, the prediction of the potential distribution stabilizes and does not change significantly, even if more presence points are included (Scheldeman and Zonneveld, 2010).

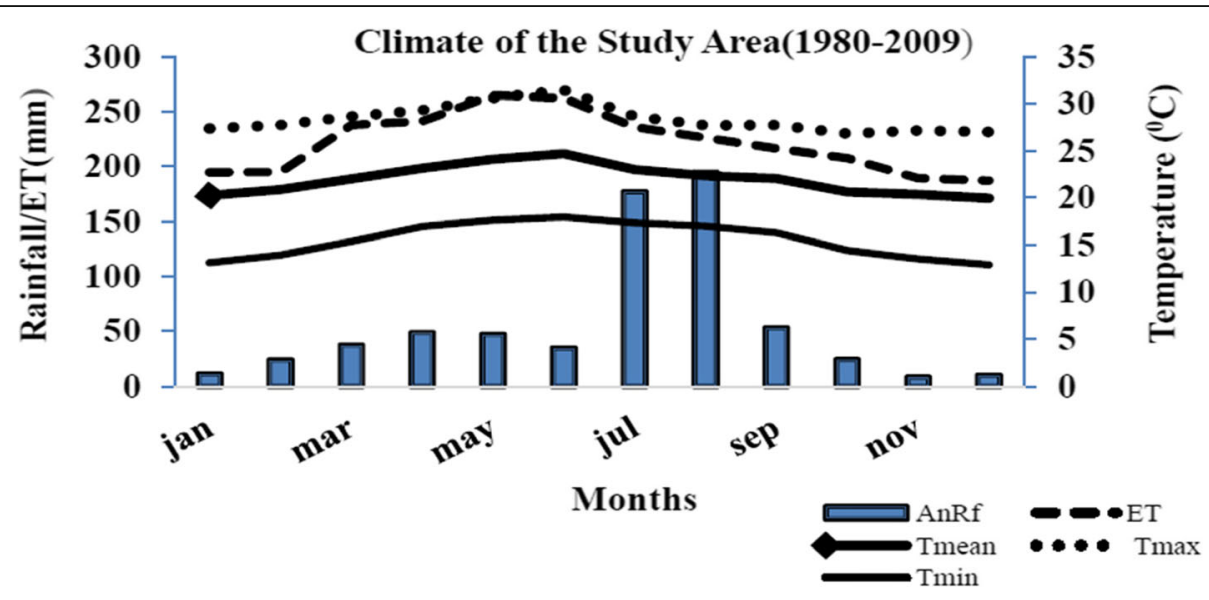

Fig. 2 Rainfall against evapotranspiration of Mehoni Station from1980 to 2009 (NMA, 2015) 


\section{Bioclim data inputs}

Bioclimatic datasets were used to construct the current and future probable distribution of cattle tick species. To quantify the environmental conditions limiting the distribution of tick species, all the 19 bioclimatic variables in the WorldClim database (Table 1) were downloaded from (http://www.worldclim.org/tiles.php?Zone=27) (Hijmans et al., 2005). The variables were selected because they have high spatial resolution and good quality, contain biologically meaningful variables, and are widely applied for ecological niche modeling having ecological contribution to influence the species distribution (Elith J, 2010; EstradaPena A, 2006; Estrada-Pena A, 2006). These raster variables have a spatial resolution of 30 arc second $\left({ }^{*} 1 \mathrm{~km}^{2}\right.$ per pixel) and were derived based on the temperature and precipitation values which were clipped using ArcGIS 10 software to the study area (Raya Azebo shape file) for use in maximum entropy (MaxEnt) model.

Projecting species distribution using only one or a limited number of climate models will sample an unknown fraction of the uncertainty in future conditions (Beaumont et al., 2008). Therefore, to estimate the current and future climate conditions, outputs from two global climate models (GCMs) and two representative concentration pathways (RCPs) (RCP 4.5 and RCP 8.5) were downloaded from (http://www.worldclim.org/cmip5_30s_ and clipped down to the study area (Raya Azebo district) extent.
Two time segments, 2050 (average for the years 20412060) and 2070 (average for the years 2061-2080), were selected. The two GCMs named ACCESS1-0 (Australian Community Climate and Earth System Simulation model) (Niguse and Aleme, 2015) and CCSM4 (Community Climate System Model) (Ruane et al., 2013) were selected based on their availability of data for the selected RCPs and time slices and widely used in the climate projections and species distribution predictions.

The outcome of the two available greenhouse gas scenarios, i.e., RCP 4.5 and RCP 8.5 (Weyant et al., 2009), was examined for each period. Thus, we had a succession of three different probable distribution maps for each scenario, i.e., for the current, 2050, and 2070 time slices.

\section{Modeling procedures for tick distribution}

In this study, MaxEnt Version 3.3.3k algorithm (https:// www.cs.princeton.edu/ schapire/maxent/) was used since it has been found to perform better than many other modeling methods to model animal and plant species (Phillips et al., 2006; Porretta et al., 2013). It relates individual specimen locations to current environmental GEO datasets to derive the probability of species occurrence (Phillips et al., 2006). It is a presence-only modeling technique rather than absence locations (Phillips et al., 2006; Phillips and Dudík, 2008).

Table 1 Code and description of variables

\begin{tabular}{llll}
\hline Code & Description & Scaling factor & Units \\
\hline Bio1 & Annual Mean Temperature & 10 & Degrees Celsius \\
Bio2 & Mean Diurnal Range (Mean of monthly (max temp - min temp) & 10 & Degrees Celsius \\
Bio3 & Isothermality (BIO2/BIO7) & 100 & Degrees Celsius \\
Bio4 & Temperature Seasonality (Standard Deviation ) & 100 & Degrees Celsius \\
Bio5 & Max Temperature of Warmest Month & 10 & Degrees Celsius \\
Bio6 & Min Temperature of Coldest Month & 10 & Degrees Celsius \\
Bio7 & Temperature Annual Range (BIO5-BIO6) & 10 & Degrees Celsius \\
Bio8 & Mean Temperature of Wettest Quarter & 10 & Degrees Celsius \\
Bio9 & Mean Temperature of Driest Quarter & 10 & Degrees Celsius \\
Bio10 & Mean Temperature of Warmest Quarter & 10 & Degrees Celsius \\
Bio11 & Mean Temperature of Coldest Quarter & 1 & Degrees Celsius \\
Bio12 & Annual Precipitation & 1 & Millimeters \\
Bio13 & Precipitation of Wettest Month & 1 & Millimeters \\
Bio14 & Precipitation of Driest Month & 100 & Millimeters \\
Bio15 & Precipitation Seasonality ( Coefficient of Variation ) & 1 & Fraction \\
Bio16 & Precipitation of Wettest Quarter & 1 & 1 \\
Bio17 & Precipitation of Driest Quarter & 1 & Millimeters \\
Bio18 & Precipitation of Warmest Quarter & Mrecipitation of Coldest Quarter & Millimeters \\
Bio19 & & 10 & Millimeters \\
\hline
\end{tabular}


Current and projected probable distributions for the cattle tick were built with the presence data points and the 19 climatic variables using MaxEnt algorithm. All of these were used to produce current and future (2050 and 2070) maps of probability of species distribution. MaxEnt was able to produce a raster that automatically displays habitat suitability or distribution map in the range of 0-1 (logistic output). A 90\% sensitivity criterion was used to distinguish suitable from unsuitable habitat, whereas the remaining $10 \%$ were used to calibrate. These graphic images were then being transferred to ArcGIS 10 using the ASCII to Raster tool. The threshold maps for the two GCMs were computed after the ASCII file was generated by the MaxEnt run, and the model was able to produce predicted potential distribution areas under future projections.

To calculate the future increase of the distribution area in respect to the present model, presence/absence maps using the minimum training presence threshold were constructed using the geographical information system (GIS) tool for analysis and management. To interpret the variation in prediction, differences in future distribution were calculated as of the current distribution because of the uncertainty in climate models (Bourou et al., 2012); average of the two GCMs was used. The threshold maps of the current and future distributions were subtracted in ArcGIS using map algebra tool to produce the difference map of the current and future. Then, the predicted potential distribution maps (projected difference map) of the district under the current and future conditions were compared. The current and future distribution area coverage in square kilometer of the tick species and the trend was also computed under the two RCPs using DIVA-GIS software version 7.5.

\section{Model outputs}

MaxEnt model has three major output data: raw, cumulative, and logistic formats (Phillips and Dudík, 2008). In our study, logistic output was selected since it is easy to conceptualize and can be interpreted as an estimate of the probability of presence for any given location ranging from 0 to 1 , where 0 signifies a very low probability of species presence and 1 a very high relative probability (Phillips et al., 2006; Signorini et al., 2014).

Jackknife results, which were displayed by MaxEnt (using logistic output), showed how the predictions depend on the variables, which greatly facilitates the interpretation of a species' ecological niche and its defining or limiting environmental factors (Buermann et al., 2008; Yost et al., 2008). Finally, only those variables that showed significant contribution for all assessment methods scored by the model were considered.

\section{Model evaluation}

One way to evaluate model performance is to use the random test percentage setting in MaxEnt (Scheldeman and Zonneveld, 2010). Area under the curve (AUC) of the receiver operating characteristic (ROC) plots provided by MaxEnt was used to define thresholds of the accuracy (Baldwin, 2009).

To develop ROC plot, the $75 \%$ observed species points were used to calibrate the model (training data) and the remaining $25 \%$ of the observed species points were used to evaluate and predict models' accuracy (Mbatudde et al., 2012). Besides, 15 replicates and 5000 iterations were set in the MaxEnt environment for validating the model robustness (Young et al., 2011).

The area under curve (AUC) is a plot of sensitivity (sensitivity representing how well the data correctly predicts presence) and 1-specificity (specificity provides a measure of correctly predicted absences) (Fielding and Bell, 1997). The scores also served as threshold-independent measure of the model performance in terms of sensitivity and specificity (Phillips et al., 2006). The AUC values typically range between 0.5 (indicate a fit no better than that expected by random) and 1.0 (indicate a perfect fit), while values less than 0.5 indicates that a model fits worse than random (Engler et al., 2004) and the AUC values for the model were interpreted as Excellent if AUC > 0.90; Good if $0.80>$ AUC $=0.90$; Acceptable if 0.70 $>\mathrm{AUC}=0.80$; $\mathrm{Bad}$ if $0.60>\mathrm{AUC}=0.70$; and Invalid if $0.50>$ AUC $=0.60$ (Araujo et al., 2005).

\section{Results}

Tick distribution under climatic conditions Model performance and influencing factors

The MaxEnt model produced a distribution map of ixodid ticks of cattle breeds across the district at $1-\mathrm{km}$ spatial resolution. The average area under the ROC curve for both training and testing is almost identical. The average AUC test for the 15 replicate runs was 0.990, and the standard deviation is 0.002 (Fig. 3); the value indicates "Excellent" predictive performance for the model.

The MaxEnt software provides an analysis regarding the contribution of each variable used for the construction of the model. The final model produced only five variables being the most important variables in the three jackknife plots (Fig. 4) listed in Table 2 based on their contribution. Precipitation of the coldest quarter (Bio19), temperature annual range (Bio7), annual precipitation (Bio12), maximum temperature of the warmest month (Bio5), and precipitation of the driest quarter (Bio17) were the most influential predictors of cattle tick distribution. Bio12 and Bio7 were highly used by the model construction though the 


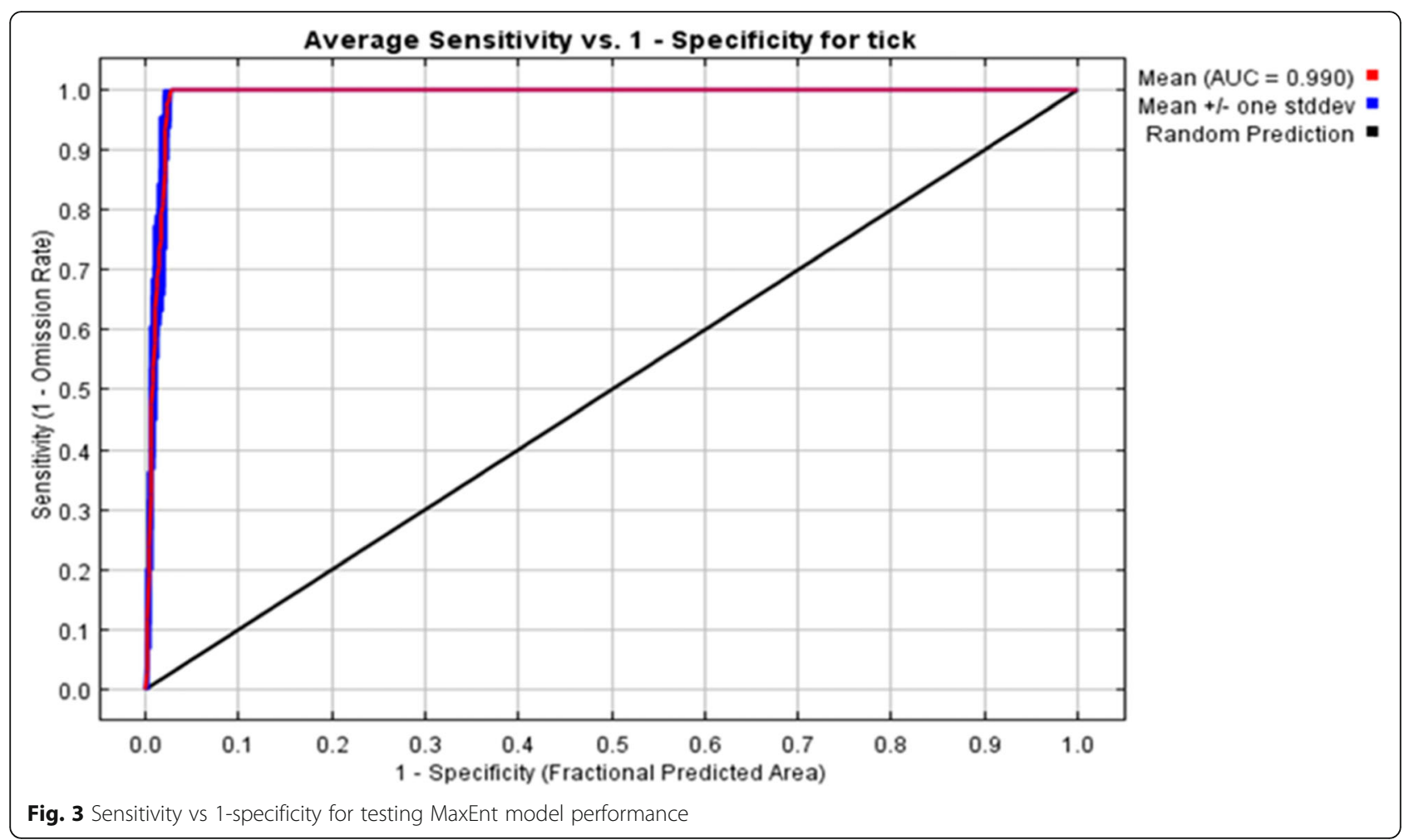

average relative contribution of the predictors of cattle tick species distribution varied (Table 2).

Moreover, Bio19, Bio17, and the least Bio5 were identified as the second most important variables in this finding. Using the relative contribution importance and three jackknife tests which signify these variables seemed to have the most useful information by itself after deleting the zero contribution of the environmental factors. Meaning, zero contribution factors have no any importance on predicting the occurrence of the species. The variable Bio5 appeared to have most information that is not present in the other variables but later fell down since it resulted in negative test gain and AUC, and the model predictive performance improved when it was not used for both test and AUC jackknife tests.

\section{Potential geographic distribution (binary results)}

Considering the future climate impact, future cattle tick distribution map was developed for both 2050 and 2070 time slices using the two different RCPs (RCPs 4.5 and 8.5). The distribution of cattle tick species is expected to increase in the future as compared to its current distribution in the study area. The model predicted higher risk of tick prevalence than currently present. Based on this, the output probability occurrence values were segmented in to five equal area categories to represent the ranges of cattle tick distribution (Fig. 5). Currently 811 $\mathrm{km}^{2}$ is found to be high, medium, low, and very low suitable areas for cattle tick distribution. About $38.2 \%$ of the land was found being occupied. The current predicts distribution of cattle tick species occurrence in the study area showed that the probability of the species to occur in most of the red and orange colored areas as these areas are highly to medium suitable for tick existence.

Regarding the projected tick distribution, both RCPs indicated an increase in suitable area from the current to 2050 and 2070 (Fig. 5). The model predicted higher risk of species incidence where a small area showed tick presence at present. It will expand from 811 to $943 \mathrm{~km}^{2}$ and $1075.5 \mathrm{~km}^{2}$ under RCPs 4.5 and 8.5, respectively, during the 2050 and expands to 876.5 and $1020 \mathrm{~km}^{2}$ under RCPs 4.5 and 8.5 , respectively, during the 2070 . The cattle tick distribution will be increased by $16.3 \%$ and $32.6 \%$ under RCPs 4.5 and 8.5 , respectively, during 2050 and increased by 8.1 and $25.8 \%$ under RCPs 4.5 and 8.5, respectively, during 2070 when compared with the current distribution map. From the two greenhouse gas scenarios, the highest degree of potential distribution change for the cattle tick was the most remarkable scenario (RCP 8.5) both for 2050 and 2070 time slices. However, the area decreased in the 2070 time slice due to the fact that some area in this district would become unsuitable in this scenario.

\section{Discussions}

Tick distribution under current and future climatic conditions

The contribution of variables to the model accuracy was determined according to Young et al. (2011) who stated 


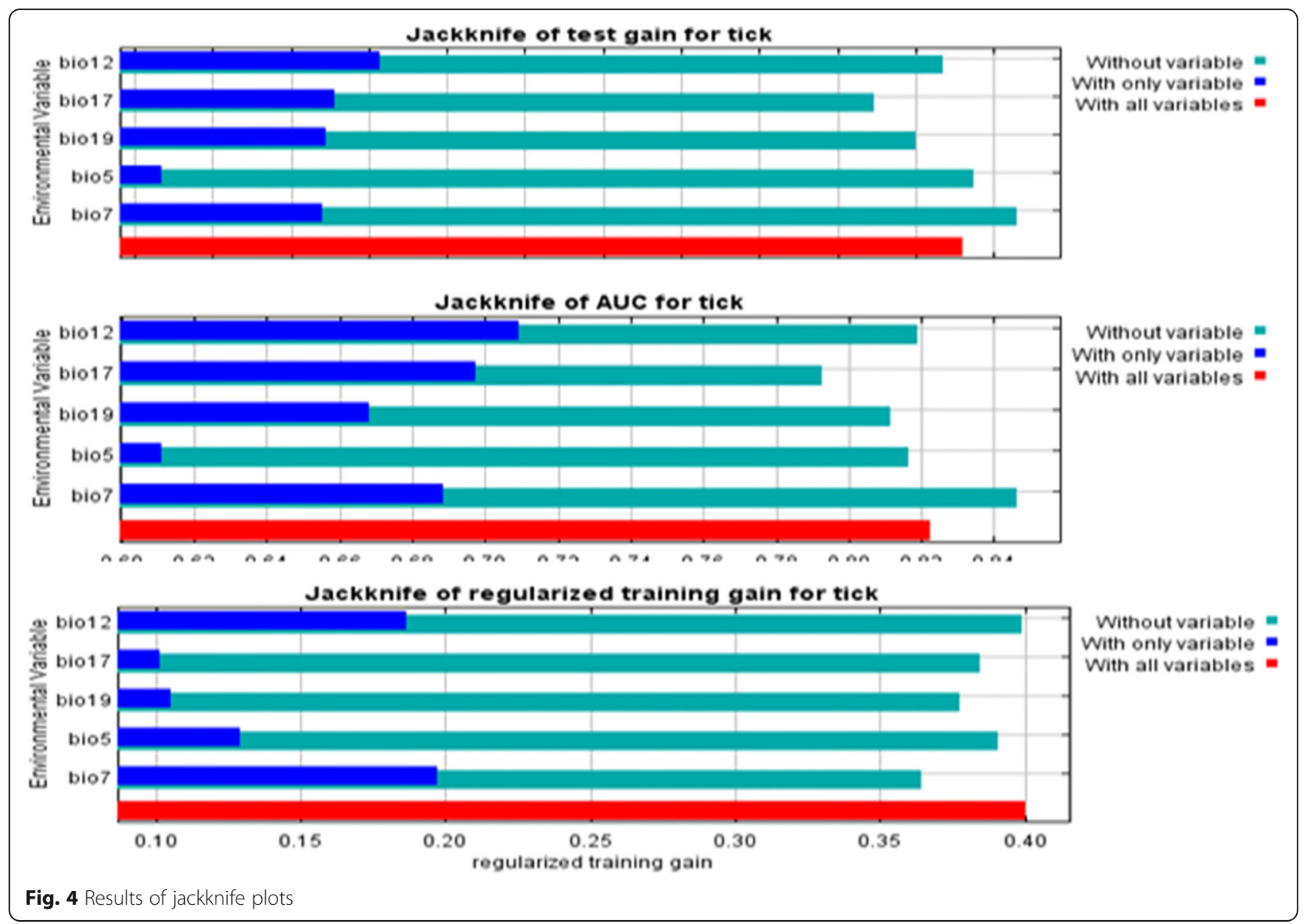

that "the higher the variable scored the percentage of contribution, the more impact that particular variable has on predicting the occurrence of the species". Considering this statement, temperature annual range (Bio7) and annual precipitation (Bio12) are the most important variables to explain the cattle tick distribution (Feilhauer et al., 2012). Thus, annual temperature range and precipitation were capable of predicting the current and future distribution of cattle ticks in the district.

Similar result was found out by Gray et al. (2009) while modeling the climate change effect on ticks distribution. The warmer annual temperature ranges and changing annual precipitation patterns have been also suggested by Lindgren and Jaenson (2006) as the main derivers of tick to distribute to new areas. Leta et al.

Table 2 Contribution of environmental variables

\begin{tabular}{llllll}
\hline Time Slices & \multicolumn{5}{l}{ Variables Contribution } \\
\cline { 2 - 6 } & Bio7 (\%) & Bio12 (\%) & Bio 19 (\%) & Bio 17(\%) & Bio 5(\%) \\
\hline 2050_RCP4.5 & 43.5 & 53.2 & 30.6 & 2.9 & 3.5 \\
2050_RCP8.5 & 46.9 & 31.7 & 21.3 & 19.6 & 19.3 \\
2070_RCP4.5 & 43.6 & 46.9 & 12 & 10.6 & 7.7 \\
2070_RCP8.5 & 30.6 & 58 & 11.8 & 19.3 & 9.2 \\
\hline
\end{tabular}

(2013) also argued that these two variables are the most important predictors for the specific $R$. appendiculatus tick distribution in horn Africa in general and in Ethiopia in particular, and it is predicted in areas with high precipitation and moderate temperature. Moreover, Ogden et al. (2008) also reported that certain ranges of temperature and rainfall influences tick life cycle and host-seeking activity. However, the monthly mean precipitation and temperature are most the important factors that can affect cattle tick distribution (Cumming, 2002).

\section{Impact of climate change on cattle tick distribution}

For the cattle tick distribution, the changing climate could play a crucial role in expanding their habitat suitability. Modeling the current and future distribution of animal and plant organisms in relation to climate change envelopes in terms of geographic range change, the dynamic biological abundance and the pathogen would be useful for advanced studies on climate change-resilient and adaptation practices, formulation epidemiologic policies, and/or health-related policies and nature conservation (Howden et al., 2007; Parmesan et al., 2013; Pindyck, 2013; Wardrop et al., 2013). 


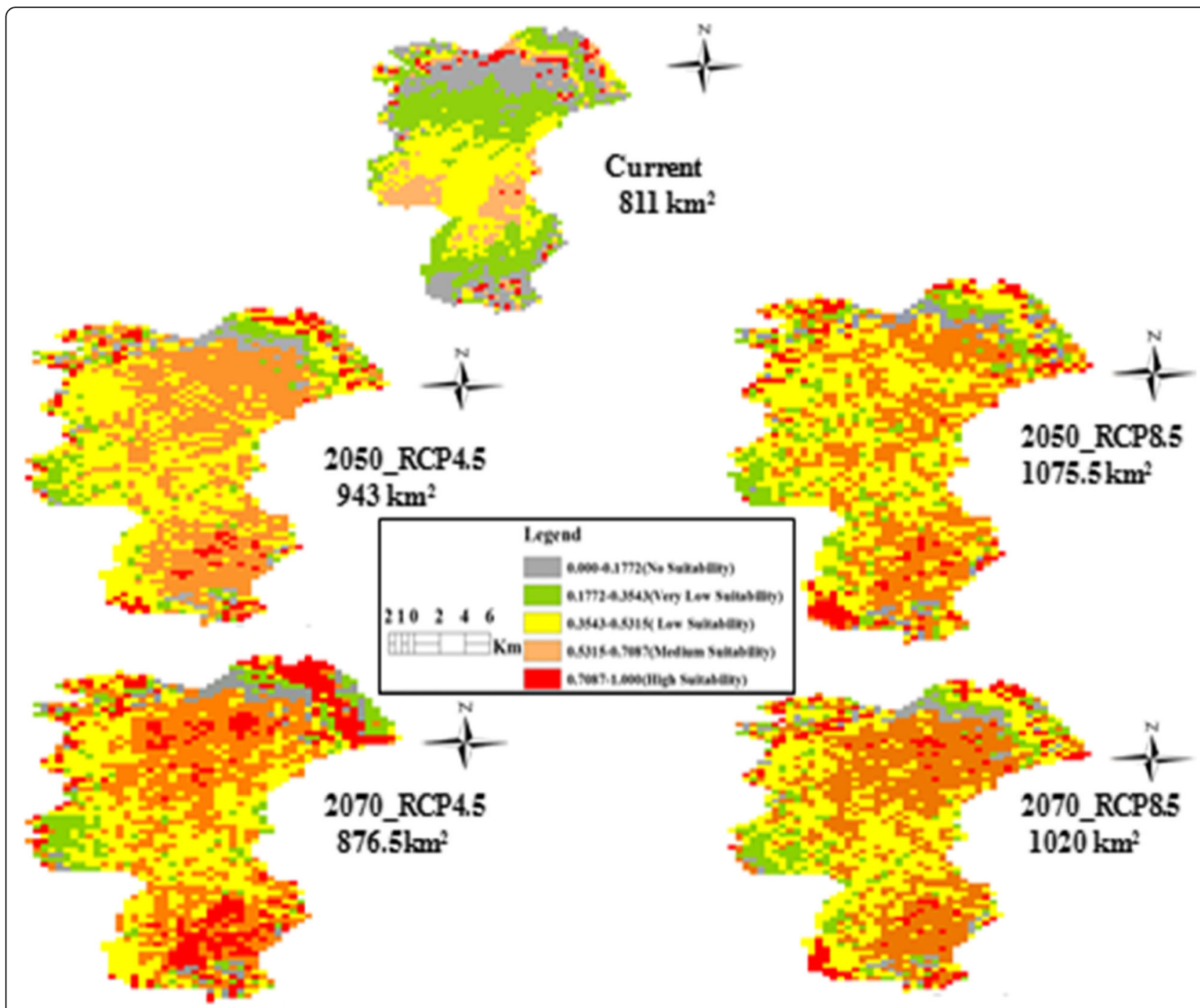

Fig. 5 Current and future genus Rhipicephalus tick distribution map

According to different scholars, studies related to species distribution were carried out at global scale and local scale (Khormi and Kumar, 2014; Lafaye et al., 2013). Climate suitability predictions for tick distribution studies in relation to climate change modeling required to take responsibilities for global and regional distributions maps, e.g., for $H$. marginatum (Estrada-Peña and Salman, 2013) and R. annulatus (Williams et al., 2015), while modeling climate-induced impacts on the current and future cattle tick distribution like this study are limited at the national scale. On the other way, this paper could have the first approach at the local scale to model future distribution maps for cattle tick species in the light of future climate scenarios. Our purpose was to map the current and future cattle tick distribution of the risk area of the district using the predicted models based on the most up-to-date climate scenarios.
The general trend of areal expansion towards previously unsuitable areas of this research is in line with other similar studies carried out in different areas on different tick species like Ixodes ricinus, I. scapularis, and Rhipicephalus sanguineus (Gray et al., 2009; Ogden et al., 2006; Porretta et al., 2013). The increase in temperature, which is predicted to occur in the near future (IPCC, 2007), is likely to affect the ecology and geographic distribution of many organisms, including tick species. Such rising temperature is the main influential factor to increase tick distribution and ticks' development time (Olwoch et al., 2008). For this reason, ticks may get higher chance to attach themselves to their appropriate host to get more food and shorten their hatching period besides having suitable environment for further distribution. 
Moreover, cattle ticks could have more suitable conditions to expand to new areas due to the direct effects of climate change in terms of temperature and rainfall (Gray et al., 2009) and this may power ticks and their pathogens to expand their suitable areas (Zeman and Lynen, 2010). However, this study did not have enough evidence that an increase in temperature will result in an increase in number of ticks by increasing rates of development, rather by making ticks available to new areas by changing the day length.

For all scenarios applied in this study, an increase in the potential distribution area of the targeted tick of the study area was recorded as compared to the current distribution map. The general trend of increment was more prominent in the study district, and the future distribution of the genus Rhipicephalus will increase up to $1075.5 \mathrm{~km}^{2}$. This result goes adjacent with the forecast trends made by Estrada-Peña and Salman (2013) and Cumming and Van Vuuren (2006) who reported that climate play an obvious role in stimulating the spread of ticks to the current unsuitable areas and predicted the suitability for all African tick species will be about 1-9 million $\mathrm{km}^{2}$ in the near future.

The RCP 4.5 scenario predicts around 16.3\% increase in the area for 2050 , which would rise to $8 \%$ by 2070 but decrease by $8 \%$ from the 2050 time slice. An exciting progression is shown in the case of RCP 8.5 after a large increase projected for 2050; a decrease was noticed with respect to the extent of suitable areas for the year 2070 . This result was in lined with that of Duan et al. (2016) who reported most species have large changes in RCP 8.5 during the 2070 time slice. The explanation is that, we may observe an expansion of species range towards the new areas which were previously unsuitable in the projected climate conditions of the district. Moreover, Ostfeld and Brunner (2015) discussed that the changing and warming climate will play a vital role in changing the distribution of Ixodes ticks.

\section{Conclusion and recommendations}

Modeling of the geographic distribution patterns of the genus Rhipicephalus tick shows positive distribution changes. The modeling tool is considered a useful tool for understanding the environmental requirements of this targeted tick genus and their pathogens in the semiarid areas of the study district using presence data, species distribution model (SDM), and GIS tools based on the environmental factors' contribution. While cattle tick pathogens require the presence of suitable reservoir host too, the assessment of their epidemiologic impact could not be decoupled from the geographic distribution of their cattle ticks. The present targeted genus tick displays an increase of their distribution towards presently unsuitable areas of the study district. Although the developed model demonstrates an excellent predictive power, the issue of species ecology should also be considered. The selected ixodid tick in the district depends for parts of their life on the availability of suitable hosts, so the climate is only one essential determinant of their occurrence. As the climate change will very likely affect the hosts as well, this in turn can affect the cattle tick distribution. Therefore, the present and future distribution of the targeted tick due to the changing climate may worsen the food insecurity problem in general and the cattle production in particular which the people of the district are facing.

Based on the present findings of this study, the following points are recommended to respond to the main impacts of climate change on cattle production through influencing the future tick distribution of the district.

$\checkmark$ Strengthening the early warning system to provide timely information about the climate change and variability's effect on cattle directly and/or indirectly which then help to develop preventive actions to the climatic impacts should be primary action for the future.

$\checkmark$ Community awareness about future impacts of climate change on cattle, tick occurance, and control strategies should be implemented.

\section{Need for future research areas}

$\checkmark$ Future impact of climate change on tick species abundance, distribution and tick-borne disease distribution, and cattle dynamics considering soil temperature, humidity, vegetation index, competition, host type, and other factors that have not been accounted in this study.

\section{Abbreviations}

MaxEnt: Maximum entropy; AUC: Area under the curve; RCP: Representative concentration pathways; SDM: Species distribution model; Ethio-

DEM: Ethiopian-Digital Elevation Model; RUFORUM: Regional Universities Forum; NMA: National Meteorological Agency; IPCC: Intergovernmental Panel on Climate Change; ET: Evapotranspiration; GPS: Global Positioning System; GCMs: Global climate models; ACCESS1-0: Australian Community Climate and Earth System Simulation model; CCSM4: Community Climate System Model; GIS: Geographical information system; ROC: Receiver operating characteristic

\section{Acknowledgements \\ The authors would like to thank the owners of the examined local cattle breeds for their cooperation during the sample collection and the district staff members of the office of agriculture and veterinary clinic experts for their endless support and for providing a reliable and essential data for this study. The authors acknowledge the Regional Universities Forum (RUFORUM) under the project for crop-livestock value chain for the financial support and the Institute of Climate and Society of Mekelle University for the technical support.}

\section{Authors' contributions}

All authors participated in the design of the study and conducted the fieldwork. All authors analyzed and interpreted the data and participated in the development of the manuscript. All authors read and approved the final manuscript.

\section{Funding}

This work was supported by the Regional Universities Forum (RUFORUM) under the crop-livestock value chain project for financial Research Grant and 
Institute of Climate and Society of Mekelle University for the technical Support.

\section{Availability of data and materials}

The datasets generated during and/or analyzed during the current study are available from the corresponding author on reasonable request.

\section{Ethics approval and consent to participate}

Not applicable

\section{Consent for publication}

Not applicable

\section{Competing interests}

The authors declare that they have no competing interests.

\section{Author details}

${ }^{1}$ Tigray Agricultural Marketing Promotion Agency, Mekelle, Ethiopia. ${ }^{2}$ Institute of Climate and Society, Mekelle University, Mekelle, Ethiopia. ${ }^{3}$ College of Veterinary Medicine, Mekelle University, Mekelle, Ethiopia. ${ }^{4}$ Department of Land Resource Management and Environmental Protection, Mekelle University, P O Box 231, Mekelle, Ethiopia.

Received: 23 July 2019 Accepted: 12 November 2019

Published online: 29 December 2019

\section{References}

Araujo MB, Pearson RG, Thuiller W, Erhard M. Validation of species-climate impact models under climate change. Global Change Biol. 2005:11:1504-13.

Aydinalp C, Cresser MS. The effects of global climate change on agriculture. Am Eurasian J Agric Environ Sci. 2008;3:672-6.

Baldwin RA. Use of maximum entropy modeling in wildlife research. Entropy. 2009;11:854-66

Beaumont $\amalg$, Hughes $L$, Pitman A. Why is the choice of future climate scenarios for species distribution modelling important? Ecol Lett. 2008;11:1135-46.

W Bewket, MAO Radeny, C Mungai (2015). Agricultural Adaptation and Institutional Responses to Climate Change Vulnerability in Ethiopia.

Bourou S, Bowe C, Diouf M, Van Damme P. Ecological and human impacts on stand density and distribution of tamarind (Tamarindus indica L.) in Senegal. Afr J Ecol. 2012;50:253-65.

Buermann W, Saatchi S, Smith TB, Zutta BR, Chaves JA, Milá B, Graham CH. Predicting species distributions across the Amazonian and Andean regions using remote sensing data. J Biogeography. 2008;35:1160-76.

Calvosa, C., Chuluunbaatar, D., and Fara, K. (2009). Livestock and climate change. In "Livestock and climate change". International Fund for Agricultural Development (IFAD).

Cumming G. Comparing climate and vegetation as limiting factors for species ranges of African ticks. Ecology. 2002;83:255-68.

Cumming GS, Van Vuuren DP. Will climate change affect ectoparasite species ranges? Glob Ecol Biogeography. 2006;15:486-97.

de la Fuente J, Almazán C, Blouin EF, Naranjo V, Kocan KM. Reduction of tick infections with Anaplasma marginale and A. phagocytophilum by targeting the tick protective antigen subolesin. Parasitol Res. 2006;100:85-91.

Duan R-Y, Kong X-Q, Huang M-Y, Varela S, Ji X. The potential effects of climate change on amphibian distribution, range fragmentation and turnover in China. PeerJ. 2016:4:e2185.

Elith J, Kearney M, Phillips S. The art of modelling range-shifting species. Methods Ecol Evol. 2010;1:330-42.

Engler R, Guisan A, Rechsteiner L. An improved approach for predicting the distribution of rare and endangered species from occurrence and pseudoabsence data. J Appl Ecol. 2004;41:263-74.

Estrada-Pena A, Bouattour A, Camicas JL, Guglielmone A, Horak I, Jongejan F, Latif A, Pegram R, Walker AR. The known distribution and ecological preferences of the tick subgenus Boophilus (Acari:lxodidae) in Africa and Latin America. Exp Appl Acarol. 2006:38(2-3):219-35.

Estrada-Pena A, Corson M, Venzal JM, Mangold AJ, Guglielmone A. Changes in climate and habitat suitability for the cattle tick Boophilus microplus in its southern Neotropical distribution range. J Vector Ecol. 2006;31(1):158-67.

Estrada-Peña A, Salman M. Current limitations in the control and spread of ticks that affect livestock: A review. Agriculture. 2013;3:221-35.
Feilhauer H, He KS, Rocchini D. Modeling species distribution using niche-based proxies derived from composite bioclimatic variables and MODIS NDVI. Remote Sensing. 2012;4:2057-75.

Fielding $\mathrm{AH}$, Bell JF. A review of methods for the assessment of prediction errors in conservation presence/absence models. Environ Conservation. 1997;24:38-49.

Gashaw T. Climate change and livestock production in Ethiopia. Adv Life Sci Technol. 2014;22:39-42

Gonzalez C, Wang O, Stavana S, Gonzalez-Salazar C, Sanchez-Cordero V, Sarkar S. Climate Change and Risk of Leishmaniosis in North America: Predictions from Ecological Niche Models of Vector and Reservoir Species. PLoS Negl Trop Dis. 2010:4(1). https://doi.org/10.1371/journal.pntd.0000585.

Gray, J., Dautel, H., Estrada-Peña, A., Kahl, O., and Lindgren, E. (2009). Effects of climate change on ticks and tick-borne diseases in Europe. Interdisciplinary perspectives on infectious diseases 2009

Hadgu M, Taddele H, Girma A, Abrha H, Hagos H. Prevalence of ixodid ticks infesting Raya cattle breeds in Semi-arid areas of Raya Azebo district, northern Ethiopia. Ethiop Vet J. 2018;22:53-64.

Hay S, Omumbo J, Craig M, Snow R. Earth observation, geographic information systems and Plasmodium falciparum malaria in sub-Saharan Africa. Adv Parasitol. 2000;47:173-215.

Hernandez PA, Graham CH, Master LL, Albert DL. The effect of sample size and species characteristics on performance of different species distribution modeling methods. Ecography. 2006;29:773-85.

Hijmans RJ, Cameron SE, Parra JL, Jones PG, Jarvis A. Very high resolution interpolated climate surfaces for global land areas. Int J Climatol. 2005;25: 1965-78.

Hoffmann I. Climate change and the characterization, breeding and conservation of animal genetic resources. Anim Genet. 2010;41:32-46.

Howden SM, Soussana J-F, Tubiello FN, Chhetri N, Dunlop M, Meinke H. Adapting agriculture to climate change. Proc Natl Acad Sci. 2007;104: 19691-6.

IPCC. Climate change 2007: The physical science basis. Agenda. 2007:6:333.

Khormi HM, Kumar L. Climate change and the potential global distribution of Aedes aegypti: spatial modelling using GIS and CLIMEX. Geospat Health. 2014;8:405-15

Lafaye M, Sall B, Ndiaye Y, Vignolles C, Tourre YM, Borchi F, Soubeyroux J-M, Diallo M, Dia I, Ba Y. Rift Valley fever dynamics in Senegal: a project for proactive adaptation and improvement of livestock raising management. Geospatial Health. 2013:8:279-88.

Léger E, Vourc'h G, Vial L, Chevillon C, McCoy KD. Changing distributions of ticks: causes and consequences. Exp Appl Acarol. 2013;59:219-44.

Leta S, De Clercq EM, Madder M. High-resolution predictive mapping for Rhipicephalus appendiculatus (Acari: Ixodidae) in the Horn of Africa. Exp Appl Acarol. 2013;60:531-42.

Lindgren, E., and Jaenson, T. G. (2006). Lyme borreliosis in Europe: influences of climate and climate change, epidemiology, ecology and adaptation measures. WHO Regional Office for Europe Copenhagen.

Mannelli A, Bertolotti L, Gern L, Gray J. Ecology of Borrelia burgdorferi sensu lato in Europe: transmission dynamics in multi-host systems, influence of molecular processes and effects of climate change. FEMS Microbiol Rev. 2012;36:837-61.

Mbatudde M, Mwanjololo M, Kakudidi EK, Dalitz H. Modelling the potential distribution of endangered Prunus africana (Hook. f.) Kalkm. in East Africa. Afr J Ecol. 2012;50:393-403.

Medlock JM, Hansford KM, Bormane A, Derdakova M, Estrada-Peña A, George J-C, Golovljova I, Jaenson TG, Jensen J-K, Jensen PM. Driving forces for changes in geographical distribution of Ixodes ricinus ticks in Europe. Parasit Vectors. 2013;6:1

Min S-K, Zhang X, Zwiers FW, Hegerl GC. Human contribution to more-intense precipitation extremes. Nature. 2011;470:378-81.

Niguse, A., and Aleme, A. (2015). Modeling the Impact of Climate Change on Production of Sesame in Western Zone of Tigray, Northern Ethiopia. Journal of Climatology \& Weather Forecasting 2015.

Ogden N, Bigras-Poulin M, Hanincova K, Maarouf A, O'callaghan C, Kurtenbach K. Projected effects of climate change on tick phenology and fitness of pathogens transmitted by the North American tick Ixodes scapularis. J Theoretical Biol. 2008;254:621-32.

Ogden N, Bigras-Poulin M, O'callaghan C, Barker I, Lindsay L, Maarouf A, SmoyerTomic K, Waltner-Toews D, Charron D. A dynamic population model to investigate effects of climate on geographic range and seasonality of the tick Ixodes scapularis. Int J Parasitol. 2005;35:375-89. 
Ogden N, Lindsay L, Beauchamp G, Charron D, Maarouf A, O'callaghan C, Waltner-Toews D, Barker I. Investigation of relationships between temperature and developmental rates of tick Ixodes scapularis (Acari: Ixodidae) in the laboratory and field. J Med Entomol. 2004:41:622-33.

Ogden N, Maarouf A, Barker I, Bigras-Poulin M, Lindsay L, Morshed M, O'callaghan C, Ramay F, Waltner-Toews D, Charron D. Climate change and the potential for range expansion of the Lyme disease vector Ixodes scapularis in Canada. Int J Parasitol. 2006;36:63-70.

Olwoch J, Reyers B, Engelbrecht F, Erasmus B. Climate change and the tick-borne disease, Theileriosis (East Coast fever) in sub-Saharan Africa. J Arid Environ. 2008:72:108-20.

Ostfeld RS, Brunner JL. Climate change and Ixodes tick-borne diseases of humans. Phil. Trans. R. Soc. B. 2015;370:20140051.

Parmesan C, Burrows MT, Duarte CM, Poloczanska ES, Richardson AJ, Schoeman DS, Singer MC. Beyond climate change attribution in conservation and ecological research. Ecol Lett. 2013;16:58-71.

Parola P, Socolovschi C, Jeanjean L, Bitam I, Fournier P-E, Sotto A, Labauge P, Raoult D. Warmer weather linked to tick attack and emergence of severe rickettsioses. PLoS Negl Trop Dis. 2008;2:e338.

Parry, M., Canziani, O., Palutikof, J., Van der Linden, P., and Hanson, C. (2007). Contribution of working group II to the fourth assessment report of the intergovernmental panel on climate change, 2007. Climate Change 2007: Working Group II: Impacts, Adaptation and Vulnerability.

Phillips SJ, Anderson RP, Schapire RE. Maximum entropy modeling of species geographic distributions. Ecol Model. 2006;190:231-59.

Phillips SJ, Dudík M. Modeling of species distributions with Maxent: new extensions and a comprehensive evaluation. Ecography. 2008;31:161-75.

Pindyck RS. Climate change policy: What do the models tell us? J Eco Lit. 2013; 51:860-72.

Porretta D, Mastrantonio V, Amendolia S, Gaiarsa S, Epis S, Genchi C, Bandi C, Otranto D, Urbanelli S. Effects of global changes on the climatic niche of the tick Ixodes ricinus inferred by species distribution modelling. Parasit Vectors. 2013;6:271

Roura-Pascual N, Suarez AV. The utility of species distribution models to predict the spread of invasive ants ( Hymenoptera : Formicidae ) and to anticipate changes in their ranges in the face of global climate change. Myrmecol News. 2008;11:67-77

Ruane AC, Cecil LD, Horton RM, Gordón R, McCollum R, Brown D, Killough B, Goldberg R, Greeley AP, Rosenzweig C. Climate change impact uncertainties for maize in Panama: Farm information, climate projections, and yield sensitivities. Agricul Forest Meteorol. 2013;170:132-45.

Scheldeman, X., and Zonneveld, M. v. (2010). "Training manual on spatial analysis of plant diversity and distribution."

Signorini M, Cassini R, Drigo M, Frangipane di Regalbono A, Pietrobelli M, Montarsi F, Stensgaard A-S. Ecological niche model of Phlebotomus perniciosus, the main vector of canine leishmaniasis in north-eastern Italy. Geospat Health. 2014;9:193-201.

Slater H, Michael E. Predicting the Current and Future Potential Distributions of Lymphatic Filariasis in Africa Using Maximum Entropy Ecological Niche Modelling. PLOS ONE. 2012;7(2). https://doi.org/10.1371/journal.pone.0032202.

Thornton P, Van de Steeg J, Notenbaert A, Herrero M. The impacts of climate change on livestock and livestock systems in developing countries: A review of what we know and what we need to know. Agricul Syst. 2009;101:113-27.

Tokarevich NK, Tronin AA, Blinova OV, Buzinov RV, Boltenkov VP, Yurasova ED, Nurse J. The impact of climate change on the expansion of Ixodes persulcatus habitat and the incidence of tick-borne encephalitis in the north of European Russia. Global Health Action. 2011;4:8448.

Ward DF. Modelling the potential geographic distribution of invasive ant species in New Zealand. Biol Invasions. 2007:9:723-35.

Wardrop NA, Kuo C-C, Wang H-C, Clements AC, Lee P-F, Atkinson PM. Bayesian spatial modelling and the significance of agricultural land use to scrub typhus infection in Taiwan. Geospatial Health. 2013;8:229-39.

Weyant, J., Azar, C., Kainuma, M., Kejun, J., Nakicenovic, N., Shukla, P., La Rovere, E., and Yohe, G. (2009). Report of 2.6 versus 2.9 Watts/m2 RCPP evaluation panel. Integrated Assessment Modeling Consortium.

Williams HW, Cross DE, Crump HL, Drost CJ, Thomas CJ. Climate suitability for European ticks: assessing species distribution models against null models and projection under AR5 climate. Parasit Vectors. 2015;8:440.
Yost AC, Petersen SL, Gregg M, Miller R. Predictive modeling and mapping sage grouse (Centrocercus urophasianus) nesting habitat using Maximum Entropy and a long-term dataset from Southern Oregon. Ecol Inform. 2008;3:375-86.

Young, N., Carter, L., and Evangelista, P. (2011). A MaxEnt model v3. 3.3 e tutorial (ArcGIS v10). Fort Collins, Colorado.

Zeman P, Lynen G. Conditions for stable parapatric coexistence between Boophilus decoloratus and B. microplus ticks: a simulation study using the competitive Lotka-Volterra model. Exp Appl Acarol. 2010;52:409-26.

\section{Publisher's Note}

Springer Nature remains neutral with regard to jurisdictional claims in published maps and institutional affiliations.

\section{Ready to submit your research? Choose BMC and benefit from:}

- fast, convenient online submission

- thorough peer review by experienced researchers in your field

- rapid publication on acceptance

- support for research data, including large and complex data types

- gold Open Access which fosters wider collaboration and increased citations

- maximum visibility for your research: over $100 \mathrm{M}$ website views per year

At BMC, research is always in progress.

Learn more biomedcentral.com/submissions 